\title{
Pregadoras murshidat como agentes de mudança no Marrocos: uma perspectiva comparativa*
}

\author{
Moha Ennaji** $^{* *}$
}

\begin{abstract}
Resumo
As feministas marroquinas tem como objetivo promover posições de poder para as mulheres através da educação, da autoconsciência $e$ do conhecimento de novos direitos legais; $e$ também disseminando informações a respeito do novo código da família e do novo código trabalhista por meio de suas ONGs e grupos comunitários. $\mathrm{O}$ ativismo das mulheres contribuiu de maneira significativa para a democracia na sociedade marroquina devido a seu grande envolvimento nas questões sociais e políticas $e$ a seu acesso à mídia. $O$ ativismo feminino é essencial à modernização e à democracia, pois foi o movimento feminista que abriu espaço para a sociedade civil e para a cultura democrática. $\mathrm{O}$ movimento de mulheres fez também com que as autoridades se conscientizassem de que as mulheres podem ter um papel significativo em todas as instâncias da vida, inclusive no domínio religioso. O fenômeno do Murshidat é um passo pioneiro dado pelo governo para promover um Islã moderado e para lutar contra o extremismo islâmico.
\end{abstract}

Palavras-chave: Pregadoras, Murshidat, Marrocos, Islamismo.

\footnotetext{
* Recebido para publicação em dezembro de 2007, aceito em abril de 2008 [Tradução: Cecilia Holtermann].

** Rutgers University e Université Sidi Mohamed Ben Abdellah, Fès. http://iea:um5s:ac.ma
}

cadernos pagu (30), janeiro-junho de 2008:75-94. 
Pregadoras murshidat como agentes de mudança no Marrocos

Women Preachers "Murshidat" as Agents of Change in Morocco: A Comparative Perspective

\begin{abstract}
Moroccan feminists endeavour to promote women's empowerment through education, awareness, and knowledge of new legal rights; they also disseminate information about the new family code and the new labour code through their NGOs and community-based groups. Women's activism has significantly contributed to democracy in Moroccan society due to its greater social involvement in social and political affairs and due to the proliferation of women's associations, and to their access to the media. Women's activism is essential to modernisation and democracy, for it is the women's movement that has opened space for civil society and for democratic culture. Women's movement has also raised the awareness of the authorities that women can play a significant role in all walks of life, including in the religious domain. The phenomenon of the Murshidat is a pioneering step taken by the government to promote a moderate Islam and to fight Islamist extremism.
\end{abstract}

Key Words: Female Preachers, Murshidat, Morocco, Islam. 
Moha Ennaji

\section{Apresentação}

Para compreender o significado do ativismo das mulheres marroquinas, é crucial vinculá-lo à relação dialética entre a "satisfação das necessidades" e à renovação da legitimidade das autoridades. De acordo com Nancy Frazer (1989), a abordagem da "interpretação das necessidades" permite a emergência das consciências marginalizadas quando os marginalizados usam instrumentos e estratégias diferentes das usadas pelos grupos dominantes. A idéia é incorporar ONGs femininas, levando em conta a própria interpretação, as necessidades $e$ as visões de gênero e de desenvolvimento das mulheres, de maneira a atender à realidades locais e a satisfazer essas necessidades e demandas.

Este texto trata do papel da atuação das mulheres na luta contra a desigualdade de gênero, iluminando seus esforços para consolidar a democracia $e$ a justiça social e desafiar as práticas $e$ idéias tradicionais do governo.

$\mathrm{O}$ artigo compreende duas partes: a primeira trata do papel das ONGs femininas marroquinas na obtenção de poder para as mulheres e para a democratização e a feminização do espaço público. A segunda lida com a nova experiência das pregadoras mulheres, murshidat, criadas pelo governo para combater o radicalismo islâmico e enfatizar uma visão feminina do Islã, uma visão islâmica moderada de paz, solidariedade, tolerância, e respeito pelo outro.

\section{O papel das ONGs femininas}

A emancipação das mulheres $e$ as questões femininas tornaram-se recentemente um importante tema político que atrai a atenção de tomadores de decisão, ativistas, pesquisadores $e$ políticos. As organizações de mulheres marroquinas têm um papel decisivo na democratização e na modernização da sociedade. Desde os anos setenta, as ONGs femininas vêm criticando 
Pregadoras murshidat como agentes de mudança no Marrocos

severamente o modo como os tomadores de decisão ignoraram as demandas femininas de emancipação e de equidade de gênero.

Ao nível sócio-político, depois das reformas dos anos noventa (emenda da Constituição e da lei eleitoral), que levaram a uma maior democratização, um grande número de associações femininas emergiram, com grande impacto regional e nacional. Como exemplo, citamos as principais associações: Josour, L'Union Féminine Marocaine e L'Organisation Démocratique des Femmes.

Essas organizações não governamentais com freqüência estabelecem laços entre si e se comunicam formando redes. Não obstante, e apesar do dinamismo dessas organizações, as mulheres ainda são desprivilegiadas no que diz respeito a questões legais (por exemplo, no caso da poligamia e da herança), como veremos oportunamente. As forças conservadoras, por seu lado, definem o papel da mulher como limitado ao lar, à reprodução, $e$ ao cuidado das crianças.

As ONGs femininas promovem a emancipação da mulher, sua participação, mobilização social e pressões políticas que encorajam o bom governo e uma cultura de cidadãos responsáveis, e não sujeitos passivos. As ONGs femininas devem ser vistas como uma maneira de assegurar uma democracia participativa, dinâmica e equânime. As ONGs podem se tornar verdadeiras escolas de democracia, que encorajam o poder das mulheres e sua participação nas tomadas de decisões e nas questões públicas. As ONGs capacitaram as mulheres a analisar criticamente sua própria situação $e$ a definir a transformação da sociedade.

As ONGs são caracterizadas pelo seu pragmatismo e objetivos definidos, isto é, incrementar a situação sócio-econômica das mulheres, integrá-las ao desenvolvimento e assegurar sua participação na vida pública. Suas estratégias e ações são adotadas para capacitá-las a obter sustento próprio através da chegada ao poder pelas mulheres. 
A despeito de problemas relacionados à falta de treinamento, informação e conhecimentos de gerência $e$ de iniciativas, frágil comunicação, tanto interna quanto externa, e pesada dependência de agências internacionais de financiamento, as ONGs femininas do Marrocos lutam arduamente para que as mulheres cheguem ao poder através da mobilização de diferentes atores da sociedade civil, através da descentralização e do desenvolvimento do conhecimento de suas integrantes.

A rede de ONGs femininas tem proliferado pela criação de escritórios locais em todas as cidades do país. Financiadores internacionais, como o Banco Mundial, o UNIFEM, o PNUD, o FNUAP, a Comissão Européia e a UNESCO apóiam vários projetos de desenvolvimento; devido a seu apoio, essas ONGs organizaram vários seminários e mesas-redondas sobre temas estratégicos, como o combate à violência contra mulheres, o novo código de família, a obtenção de fundos, a tecnologia de informática, programas de alfabetização, etc. - cujo objetivo é dar o poder às mulheres e ampliar sua consciência crítica.

As ONGs femininas exercem atividades variadas e, como resultado, vêm acumulando uma boa experiência a respeito do desenvolvimento local; sua experiência deveria ser conhecida, estudada, e analisada profundamente, para mostrar que as mulheres marroquinas são dinâmicas e solucionadoras de problemas (ver Mernissi, 1989). As ONGs de mulheres tentam enfrentar os problemas sócio-econômicos candentes e ir à raiz de suas causas, explícita e sistematicamente. Muitas líderes das ONGs femininas (como Leila Rhiwi, da Espace Associatif Marocain, e Latifa Jbabi, da Women's Action de L'Union des Femmes) estão entre as ativistas mais influentes da região.

As ONGs de mulheres trabalham nas áreas de direitos humanos, direitos das mulheres, desenvolvimento econômico, educação, saúde, e também continuam a travar as batalhas cruciais sobre a legislação $e$ sobre os avanços $e$ recuos democráticos. Dois tipos principais de ONGs femininas podem ser descritos: o primeiro tipo oferece serviços, preenchendo as lacunas 
Pregadoras murshidat como agentes de mudança no Marrocos

deixadas pelas estruturas deficientes do Estado em termos de desenvolvimento social e econômico. Muitas associações locais tratam de problemas concretos, utilizando-se dos meios disponíveis na área. O segundo tipo se especializa na promoção da defesa e na prática de lobbies, com o objetivo de oferecer uma visão democrática da sociedade. Os grupos de direitos humanos são os melhores exemplos desse segundo tipo. Eles deram um salto qualitativo do papel defensivo de denúncia dos abusos aos direitos das mulheres, durante o regime do falecido Hassan II, para uma instância pró-ativa na promoção dos valores da democracia e dos direitos humanos. Algumas das ONGs mais ativas (como a Union de l'Action Féminine e a ADFM - Association Démocratique dês Femmes du Maroc) combinam ambas as abordagens, oferecendo, por exemplo, advogados para mulheres vítimas de violência doméstica $e$, ao mesmo tempo, pressionando por mudanças legislativas que assegurem uma melhor proteção dos direitos da mulher. Essas duas associações líderes são desenvolvimentos de seções que, originalmente, faziam parte de partidos da esquerda política.

Coalizões de ONGs a respeito de temas específicos (direitos humanos, leis sobre associações, luta contra a corrupção) tornaram-se importantes agentes políticos. O movimento de mulheres propôs, por exemplo, emendas a todas as leis relevantes (código civil, código penal, nacionalidade). As alternativas propostas por elas recebem enorme atenção da mídia e da opinião pública. Um dos marcos notáveis do movimento de mulheres foi o estabelecimento de uma cota de $10 \%$ de mulheres no Parlamento e de $20 \%$ no comitê político de alguns partidos políticos, como a Union Socialiste des Forces Populaires. Como conseqüência disso, temos agora 35 mulheres parlamentares $e$ duas ministras. Até a direita religiosa e as associações de mulheres islâmicas fizeram um forte lobby para aumentar sua representação no Parlamento. Por exemplo, Nadia Yassine, filha do xeique Yassine, líder do grupo islâmico "Al Adl wa Al Ihssan", aprovou a 
reforma da Moudawana [código familiar do Marrocos, de 2004] a favor das mulheres.

O desafio que as ONGs de mulheres enfrentam é o de elaborar estratégias autônomas e de se estabelecerem como forças de inovação, de pressão política, e de propostas, de forçarem o Estado a revisar suas políticas. A autonomia das ONGs é garantia básica de uma parceria genuína com o Estado e de cooperação com os partidos políticos.

O Marrocos talvez seja o único país no mundo árabe no qual as ativistas das ONGs femininas conseguiram obter direitos civis importantes, especialmente no que diz respeito à reforma do estatuto civil, da lei de cidadania - pela qual uma marroquina tem o direito de passar sua nacionalidade para seus filhos - e de outras políticas a favor da integração das mulheres no desenvolvimento sustentável.

Além disso, nas duas últimas décadas, muitas organizações $e$ associações femininas marroquinas em prol dos direitos das mulheres surgiram para combater a violência contra as mulheres, o analfabetismo, a pobreza das mulheres, a discriminação legal e cultural baseada em gênero, e a sub-representação das mulheres nas políticas públicas. Ainda que a maioria das ONGs femininas do Marrocos esteja nas grandes cidades como Rabat, Casablanca, Marrakesh e Fes, desde o final dos anos noventa, organizações de defesa da mulher foram criadas em cidades $e$ vilas menores em todo o país para tratar de problemas locais, específicos, das mulheres em suas regiões.

Não obstante, ainda há limitações e barreiras no caminho da emancipação e dos direitos legais das mulheres; por exemplo, o Marrocos não concordou com todos os artigos da CEDAW [Convenção para a Eliminação de Todas as Formas de Discriminação Contra as Mulheres, ONU, 1979], e não ratificou alguns acordos internacionais a favor dos direitos humanos, especialmente aqueles que dizem respeito à prostituição (1949) - e a constituição marroquina não menciona sua vinculação à quaisquer acordos e convenções internacionais. Do mesmo modo, 
Pregadoras murshidat como agentes de mudança no Marrocos

o princípio das cotas não é reconhecido oficialmente na constituição, o que implica que a representação política das mulheres depende da vontade e de decisões de líderes políticos. Vale a pena registrar, ainda, a fraca adesão do governo à proteção de mulheres ameaçadas de violência, especialmente violência doméstica, no nível legal, que dizia respeito à investigação policial, às sanções, $e$ ao aconselhamento legal a essas mulheres. É também notável que o novo "livret d'état civil" contenha quatro páginas dirigidas "às esposas", ao passo que o código de família revisado restringiu fortemente a poligamia. Por último, no novo código trabalhista, não há qualquer sanção contra o assédio sexual, tampouco garantia de equiparação salarial; as empregadas domésticas, por exemplo, geralmente super-exploradas por seus empregadores, não estão protegidas pelo novo código de emprego. No código penal, a idéia de estupro pelo marido não é mencionada pela simples razão de que o corpo da mulher casada ainda é considerado propriedade do marido.

Ainda que as mulheres marroquinas tenham obtido importantes vitórias, as ONGs femininas têm outras demandas que procuram incrementar os padrões de vida das mulheres $e$ estabelecer a igualdade dos sexos em todos os âmbitos. Demandando, por exemplo, a institucionalização do sistema de cotas, sua inclusão nos partidos políticos e nas organizações, encorajando mulheres a postular cargos e eleições, quando possível, e a ampliação de sua presença na administração.

Apesar das importantes reformas produzidas pela nova Moudawana, ainda há problemas relevantes para sua implementação. Barreiras culturais e tradições patriarcais, analfabetismo e falta de informação sobre o novo código da família impedem as mulheres de invocar seus direitos ou de denunciar crimes contra elas, como estupro, abuso de crianças, exploração sexual e violência doméstica. Ao tratar desses casos, nem sempre os advogados constroem argumentos legais baseados em tratados internacionais sobre direitos humanos. Freqüentemente, os juizes também resistem a invocar tratados 
internacionais, sob o pretexto de que as leis nas quais eles devem apoiar suas decisões não incluem leis internacionais.

As feministas marroquinas, assim, tratam de promover a conscientização e o conhecimento dos novos direitos legais entre as mulheres; elas também trabalham arduamente para disseminar informações sobre o novo código da família e o novo código trabalhista, através da rede de ONGs femininas e dos grupos comunitários.

Passemos agora à segunda parte deste texto, para discutir o lugar das religiosas pregadoras, murshidat, criadas pelo governo para restringir o extremismo islâmico e promover uma visão feminina de um islamismo moderado, de paz, solidariedade, tolerância e respeito pelo outro.

\section{As murshidat do Marrocos}

Em 28 de abril de 2006, cinquenta mulheres pioneiras se formaram numa academia para imans em Rabat, juntando-se às fileiras das poucas mulheres no mundo árabe treinadas como guias religiosas. Elas concluíram um programa multidisciplinar de doze meses no qual estudaram, além do Alcorão, do Hadith e da Charia, computação, gerenciamento de negócios, economia, sociologia, psicologia e direito.

Este programa marroquino, o primeiro do seu tipo, indica uma mudança política, cujo objetivo é promover uma imagem positiva do Islã e lutar contra o radicalismo e o terrorismo islâmico.

O impulso é reformar o Islã e enfatizar uma interpretação moderada dele. O papel das murshidat é oferecer aconselhamento religioso para mulheres e crianças nas mesquitas, escolas, hospitais, prisões e outras instituições públicas. É uma iniciativa para estabelecer contato com outras mulheres, somando-se ao controle religioso feito pelo governo.

O treinamento de guias religiosas femininas é um programa pioneiro e o primeiro experimento no mundo árabe-muçulmano, um experimento que, de qualquer perspectiva que se olhe, é um 
Pregadoras murshidat como agentes de mudança no Marrocos

passo largo e corajoso na direção certa, a ser seguida pelos muçulmanos moderados em todo o mundo.

A idéia das murshidat, lançada pelo Rei Mohamed VI e pelo governo, foi implantada depois que ataques de extremistas em Casablanca, em 16 de maio de 2003, deixaram 45 mortos, além de dezenas de feridos.

O Rei já dera início à remodelação das estruturas religiosas para limitar qualquer ação extremista no seu país do Norte da África, que faz fronteira com a Argélia, onde a violência entre as forças do governo e extremistas islâmicos armados já haviam causado mais do que 150.000 mortes desde 1992. Mas os ataques suicidas sincronizados, com bombas, que atingiram judeus e alvos estrangeiros, deram urgência à iniciativa.

Mais de duas mil pessoas foram presas na vasta operação policial depois dos bombardeios de maio, enquanto o Rei afirmava que esses ataques seriam os últimos a abalar o Marrocos. As investigações concluíram que quem estava por trás dos eventos havia buscado seus recrutas nos guetos de Sidi Soumen e em outras favelas nos arredores de Casablanca, a maior cidade do Reino.

Em seguida, o governo decidiu reformar as ações religiosas e a estrutura das mesquitas, numa vasta operação chamada, em árabe, de "al islah addini". Antes de maio de 2003, mais de um terço das mesquitas estava fora do controle do governo e era possível construir mesquitas quando e onde bem se quisesse. Com a reforma religiosa lançada pelo ministro dos assuntos islâmicos, Ahmed Taoufik, todas as mesquitas são agora controladas pelas autoridades, os imans são nomeados por esse ministério, e os sermões religiosos devem ser aprovados por autoridades religiosas do governo. Em todas as cidades, diretores e administrações islâmicas foram nomeados para controlar as atividades religiosas e os sermões em mesquitas.

De acordo com o representante do ministério Ahmed Kostas, num documentário veiculado pelo canal anglófono $\mathrm{Al}$ Jazeera em julho de 2006, 
é o momento de fazer mudanças, já que o islamismo praticado nas ruas está se tornando radical. Queremos promover uma religião que não seja contraditória com a vida moderna. "Queremos que as murshidat do Marrocos sejam um modelo para outros países muçulmanos" [acrescentou ele].

O ministério, que controla as mesquitas marroquinas, também deseja implementar um islamismo moderado, particularmente a visão feminina do islamismo, para combater o extremismo. Leila Ahmed, autora de Border Passage, confirma essa idéia ao afirmar que as mulheres egípcias têm uma visão do Islã moderada e humana, pois incentivam um islamismo de solidariedade, generosidade, diálogo, tolerância, justiça e paz. Por contraste, os homens e os dirigentes religiosos em particular, freqüentemente, são ortodoxos e seguem ideologias radicais $e$ inflexíveis. Assim, no Marrocos, são as mulheres que estão liderando o apoio a um islamismo de tolerância e paz.

Entre as funções das murshidat, podemos mencionas as seguintes:

- guiar e aconselhar as mulheres a respeito das questóes religiosas;

- ocupar-se das condutas religiosas das mulheres e das crianças;

- promover um islamismo positivo, moderado e tolerante, "acompanhar e orientar" mulheres e crianças muçulmanas, especialmente em prisões, hospitais, e escolas;

- ser "exibidas como a vanguarda na luta contra qualquer desvio em direção a um islamismo extremista", como disse orgulhosamente Mahammad Mahfudh, diretor do centro vinculado ao ministério dos assuntos islâmicos que treinou a primeira classe de 50 mulheres;

- As murshidat vão trabalhar com mulheres e crianças particularmente nos guetos pobres, vistos como solo fértil para recrutadores extremistas. 
Pregadoras murshidat como agentes de mudança no Marrocos

\section{"A Fatwa marroquina declara que as mulheres não podem puxar as orações"}

Apesar de seu excelente treino e suas obrigações, as murshidat não estão autorizadas a puxar orações ou a ocupar o posto de iman, decidiu a autoridade religiosa oficial marroquina, com base no fato de que nunca na história do Marrocos as mulheres puxaram orações ou foram imans.

A regra não afeta o trabalho das murshidat, mas impede as mulheres de ampliarem seu papel, puxando orações ou tornandose imans. No entanto, de acordo com a escola de Maliki, é permitido às mulheres puxarem orações em comunidades compostas só de mulheres. Para Ahmed Kostas, representante do ministério, é muito melhor para as murshidat aconselhar e ensinar mulheres e crianças a prática de um islamismo moderado, do que simplesmente puxar orações nas mesquitas. Isso tem um impacto positivo muito maior na sociedade como um todo.

\section{Perfil e atitudes das murshidat}

Todas as pregadoras religiosas têm títulos universitários, sendo bacharéis em Estudos Árabes ou Islâmicos por universidades marroquinas. Elas dominam muito bem a língua árabe e têm um bom conhecimento do Alcorão, do Hadith e da lei da Charia (islâmica). Perguntei a algumas dessas murshidats sobre seu novo papel e novas tarefas:

Samira Marzouk, com cerca de 30 anos, como a maior parte das outras, afirma seu "orgulho" por fazer parte desse primeiro grupo e vê sua missão como a de

preencher as lacunas que impedem uma delimitação sólida para a religião. Vamos ensinar a respeito de um islamismo tolerante, particularmente nas classes desfavorecidas. As murshidat serão encarregadas de liderar discussões religiosas, dar lições de islamismo, dar apoio moral às 
pessoas com dificuldades, e guiar os fiéis em direção de um islamismo tolerante.

Uma pioneira, Samira Marzuk, diplomada em Literatura Árabe e que diz conhecer o Alcorão de cor, esclareceu depressa que "não iria tomar o lugar de um iman. O lugar de iman no islamismo é reservado apenas aos homens, que estão qualificados para dirigir as preces, especialmente as de sexta-feira".

Outra formada, Leila Faris, uma jovem viva, diplomada em Estudos Islâmicos, disse que o papel das murshidat é promover

a verdadeira face do Islã. Vamos ajudar a atenuar qualquer desvio em direção ao extremismo islâmico [diz ela, enfatizando que] é necessária uma abordagem global para lidar com o islamismo radical. O esporte foi a única matéria excluída do treinamento das pregadoras, porque o currículo estava muito carregado [lamentava Mahfudh, que espera que ele seja incluído na segunda leva de treinamento, cujas matrículas estão abertas agora].

Para o ministro dos assuntos islâmicos, Ahmed Taoufiq, as murshidat também "ensinarão as mulheres seus deveres islâmicos básicos". Ele disse que o radicalismo religioso não era parte da cultura do Marrocos, "mas nunca se pode prevenir o mal com cem por cento de sucesso".

\section{Atitudes em relação às murshidat}

A sociedade marroquina está observando as murshidat e vigiando se se comportam bem e se vão obter sucesso em sua missão. Como dito acima, suas funções são múltiplas. Elas são conselheiras religiosas e sociais e têm um aspecto político.

Os fundamentalistas islâmicos marroquinos estão divididos em relação à iniciativa. Infelizmente, ainda há alguns fundamentalistas islâmicos no Marrocos que não apóiam essa iniciativa. Mas, para Mustafá Ramid, membro do parlamento, do 
Pregadoras murshidat como agentes de mudança no Marrocos

partido da Justiça e Desenvolvimento Islâmico (PJD), o principal grupo de oposição, com 43 lugares num parlamento de 325 membros, as murshida são um desenvolvimento "positivo". "Não vejo nada mais a dizer a respeito da iniciativa, porque no islamismo homens e mulheres são iguais", disse ele, observando que no Egito e no Marrocos há "eminentes mulheres estudiosas do Islã”.

Mas o líder do grupo de jovens da associação fundamentalista islâmica mais radical do Marrocos - Al-Adl WalIhssane (Justiça e Bem-Estar) - dirigido por Abdeslam Yassine, prevê que não haverá efeitos sociais. "O poder por trás dessa iniciativa é o mesmo que comete atos contrários ao Islã, especialmente rebaixando os padrões morais", disse Hassan Bennajih, cujo grupo é parte de um movimento islâmico que prega a não violência e não é reconhecido pelas autoridades, ainda que seja influente. "Esta iniciativa vai ter impacto limitado sobre a população", diz Bennajih.

No entanto, para a intelectualidade progressista e para a maioria dos marroquinos, esse é mais um passo em direção à tolerância, à igualdade e à modernidade, a ser aplaudido.

$\mathrm{O}$ experimento marroquino das murshidat foi tão bemsucedido que alguns poucos países muçulmanos, como o Egito, decidiram se inspirar no modelo do Marrocos.

\section{As murshidat do Egito}

Um ano depois de as murshidat marroquinas começarem seu trabalho, o governo egípcio seguiu os passos do Marrocos, treinando também 50 mulheres pregadoras, igualmente chamadas murshidat, para aconselhar as mulheres egípcias em questões religiosas.

A decisão do Ministério de Assuntos Religiosos do Egito, de treinar suas murshidat num curso de quatro anos na universidade islâmica mais importante, a al-Azhar, foi bem recebida pelos homens e mulheres egípcios. A guia espiritual feminina chefe, 
Samira Rifat Abul Kheir, é uma "daa'iya", um papel que já existe para ajudar as mulheres muçulmanas.

As mulheres religiosas precisam de uma mulher para pedir conselhos, porque é difícil para elas colocar certos temas $e$ questões pessoais para o iman na mesquita, muitas delas não conseguem vencer seu embaraço [disse Samira à Adukronos International (AKI), numa entrevista].

A decisão do ministério de assuntos religiosos de criar as murshidat (pregadoras femininas ou guias espirituais) mostra a atenção que os egípcios dão à mulher muçulmana em nosso país [disse ela].

Pela primeira vez na história do Egito, vários governadores nomearam mulheres para serem treinadas como murshidat, anunciou o ministro dos assuntos religiosos Hamdi Zaqzoud. Samira divide sua vida entre sua família, a frequência à mesquita, o ensino e o trabalho assistencial.

Mulher de um funcionário do Ministério de Assuntos Religiosos, ela tem seu próprio programa islâmico no canal de televisão egípcio An Nas (O Povo). Samira, diplomada em Ciência Política pela Universidade de Bern, é uma das "daa'iya" mais procuradas por mulheres em busca de respostas para questões religiosas que afetam sua vida pessoal e familiar.

Percebi que não sabia virtualmente nada sobre o Islã $e$ passei cinco anos estudando aqida (doutrina islâmica) e fiqh (leis islâmicas), tajweed (recitando o Alcorão), bem como a Sunna (tradições religiosas) e as bases de nossa religião. Hoje estou satisfeita com meu conhecimento desses temas $e$, com a ajuda de Deus, procuro estender a mão aos que estão à minha volta [disse ela].

Depois de cuidar das tarefas domésticas em sua casa, no distrito de Heliopolis, no Cairo, no qual ela vive com o marido e o 
Pregadoras murshidat como agentes de mudança no Marrocos

filho de um casamento anterior, Samira vai para a escola na qual leciona.

Há cerca de 900 crianças nas classes da manhã e 600 mulheres à tarde. As classes à tarde são para mulheres que não tiveram a oportunidade de estudar o Alcorão e que desejam ampliar sua compreensão de sua fé.

Mas seu "emprego principal" é aconselhar religiosos $e$ pessoais aos que a consultam, especialmente mulheres.

Recebo pessoas na mesquita, depois das preces vespertinas, e elas me questionam sobre vários temas. Na maior parte dos casos, trata-se de mães que tem problemas de comunicação com seus filhos, ou esposas querendo saber como viver suas relações como parte de um casal sem contrariar os preceitos do Alcorão, mas também jovens mulheres inseguras sobre se devem ou não usar o véu, ou jovens esposas querendo saber se podem ter relações sexuais quando estão menstruadas.

Nos últimos anos, conversando com as pessoas nas mesquitas, percebi o quanto há necessidade de mulheres pregadoras, com as quais elas não se sintam constrangidas de perguntar que roupa íntima usar durante as preces $e$ como fazer suas abluções [concluiu Samira].

As 50 murshidat - guias espirituais femininas - que concluíram seu treinamento na prestigiosa Universidade al-Azhar no Cairo, foram alocadas em 90 mesquitas, no Cairo, em Giza e Alexandria.

"Elas sabem o Alcorão de cor, estudaram a jurisprudência islâmica e são muito persuasivas", disse o sub-secretário do Ministério dos Assuntos Religiosos, xeique Abdul Latif Auoub, à imprensa local, descrevendo a iniciativa como "uma maneira de atender às necessidades das pessoas religiosas". Muitas mulheres sentem-se mais confortáveis com uma interlocutora feminina quando tratam de assuntos específicos das mulheres. 
Mohammed Abdoul Rahman, do Ministério dos Assuntos Religiosos, explicou que a idéia de nomear mulheres pregadoras surgiu num momento em que "a ética islâmica parece estar em declínio", com o crescimento das "uniões ilícitas, como os quatro milhões de casamentos 'orfi' (secretos) existentes no Egito".

O papel delas não deve ser apenas o de pregar, mas o de intervir em questões sociais, resolvendo crises familiares $e$ problemas com a educação de crianças [acrescentou Saed Mohammed, da Universidade al-Azhar].

A nomeação de guias espirituais femininas, com as tarefas de dar aulas sobre o islamismo, liderar as crentes, e fazer o papel do iman em setores femininos das mesquitas é uma completa novidade no Egito. As primeiras murshidat foram nomeadas em dezembro de 2006.

Uma das principais diferenças entre o Marrocos e o Egito é o fato de que enquanto no Egito a Universidade Islâmica al-Azhar, do Cairo, dita as regras e práticas religiosas para o governo e para a sociedade, no Marrocos, o Rei, como Comandante dos Crentes, tem autoridade para tomar decisões nas questões islâmicas e para adotar medidas que implementem as reformas religiosas. O Rei do Marrocos detém tanto o poder político quanto o religioso, e é a suprema autoridade religiosa no país, o que torna relativamente mais fácil do que no Egito fazer reformas como a do Código da Família. No Egito, o governo detém apenas o poder político e a Universidade al-Azhar detém a autoridade religiosa, que às vezes contradiz as decisões governamentais ou se opõe às reformas propostas pelo governo.

\section{Conclusão}

$\mathrm{O}$ ativismo das mulheres feminizou a sociedade civil no Marrocos devido ao seu grande envolvimento com questões sociais e políticas, à proliferação das associações femininas e a seu acesso à mídia. Desde o início dos anos 1980, a natureza da esfera 
Pregadoras murshidat como agentes de mudança no Marrocos

pública mudou, graças às contribuições das mulheres $e$ à sua participação na vida pública, motivada por suas aspirações de igualdade e de direitos civis.

A sociedade civil democrática e feminista teve sucesso na reforma do Moudawana, que não é mais considerado um texto sagrado. Embora no passado o Moudawana fosse tratado como o sagrado Alcorão, ele agora se parece mais às leis seculares, mais aberto ao debate. As ONGs femininas argumentam que se deve deixar uma porta aberta para a criatividade e para a pesquisa acadêmica em questões relevantes para o Código de Família e as leis sobre ela. $\mathrm{O}$ papel das murshidat é essencial para a modernização e a democracia, já que as interpretações das mulheres sobre o Islã são compatíveis com a modernidade e a sociedade democrática.

O fenômeno das murshidat é indicativo de uma mudança drástica na política social, um sinal da vontade da elite governamental de reformar o Islã e de modernizar a sociedade. Essa reforma religiosa é hoje mais necessária do que nunca, de modo que o islamismo possa ser compatível com a democracia, os direitos humanos e a modernidade. As murshidat contribuirão para combater o extremismo e o terrorismo ao ajudar os desprivilegiados a apreender os valores e princípios verdadeiros do Islã.

Os movimentos de mulheres do tipo murshidat contribuem para a feminização do espaço público e para a consolidação do processo democrático.

\section{Referências bibliográficas}

Association DÉmocratique des Femmes du MAROC. Le Processus d'Examen et d'Evaluation des Progrès Réalisés dans la Mise en Euvre du Programme d'Action de Beijing en Afrique (Beijing +10): Rapport des ONG du Maroc, 2004. www.wildaf-ao.org

BOURQUIA, Rahma. Les Femmes: un objet De Recherche. Etudes Féminines notes méthodlologiques. Rabat, Faculté des letters et de Sciences Humaines, 1997. 
COOKE, Miriam. Women Claim Islam. Creating Islamic feminismthrough literature. New York/London, Routledge, 2001.

DAOUD, Zakia. Féminisme et politique Au Maghreb. Casablanca, Eddif, 1993.

ENNAJI, Moha. Social Policy in Morocco: History, Politics and Social Development. In: KARSHENAS, Massoud and MoghADAM, Valentine. (eds.) Social Policy in the Middle East. London, UNRISD/Palgrave, 2006, pp.109-134.

Multilingualism, Cultural Identity and Education in Morocco. New York, Springer, 2005.

. Civil Society, Gender and Social Cohesion. In: ENNAJI, Moha. (ed.) Société Civile, Genre et Développement. Fès, Fès-Saiss Publications, 2004a, pp.81-89.

Moroccan Women and Development. In: SADIQI, Fatima. (ed.) Femmes Méditerranéennes. Fès, Fès-Saiss Publications, 2004b, pp.39-46.

and SADIQI, Fátima. The Feminization of Public Space: Women's Activism, the Family Law, and Social Change in Morocco. Journal of Middle East Women's Studies (JMEWS), Indiana, Indiana University Press, 2006.

. Migration and Gender in Morocco. Trenton, Africa World Press (to appear).

Frazer, Nancy. Feminist Talk and Talking about Feminism. Oxford, Oxford University Press, 1989.

HAENNI, Patrick. Le théatre d'ombre de l'Action Féminine. Femmes, Etat et société civile au Maroc. Paris, 1993.

KHATIBI, Abdlkebir. L'Alteranance et les Partis Politiques. Casablanca, Eddif, 1998.

MERnISSI, Fatima. Doing Daily Battle. New Jersey, Rutgers University Press, 1989.

RHIwI, Leila. Mouvement des Femmes Au Maroc. Rapport Du Social, Rabat, OKAD, 2000.

SADIQI, Fatima. Women, Gender and Language in Morocco. Leiden/ Boston, Brill Academic Publishers, 2003.

SAGHRI, Saghiri. Femmes Du Maroc, n 63, March 2001. 
Pregadoras murshidat como agentes de mudança no Marrocos

SAPIRO, Virginia. When are interests interesting? In: PHILIPS, Anne. (ed.)

The Problem of Political Representation of Women in Feminism and Politics. Oxford/New York, Oxford University Press, 1998.

Young, Iris Marion. Polity and Group difference: A critique of the ideal Universal Citizenship. In: PHILIPS, Anne. (ed.) Feminism and Politics. Oxford/New York, Oxford University Press, 1998.

\section{Links}

http://english.aljazeera.net/NR/exeres/A.htm

(http://english.aljazeera.net/NR/exeres/55410875-6CFA-4E19-9147-

BDCB6ED3815A.htm)

Islam vs Muslim Terrorists

(http://www.hipforums.com/forums/showthread.php?t=159271)

Islam denounces terrorism.com

(http://www.hipforums.com/forums/showthread.php?t=160105) 